\title{
El Rocío de Gerald Brenan, una autoetnografía epistolar
}

\section{Gerald Brenan's Rocío, an epistolary autoethnography}

\author{
Michael D. Murphy \\ Catedrático. Departamento de Antropología. Universidad de Alabama, Tuscaloosa (Alabama, EE. UU.) \\ mdmurphy@as.ua.edu
}

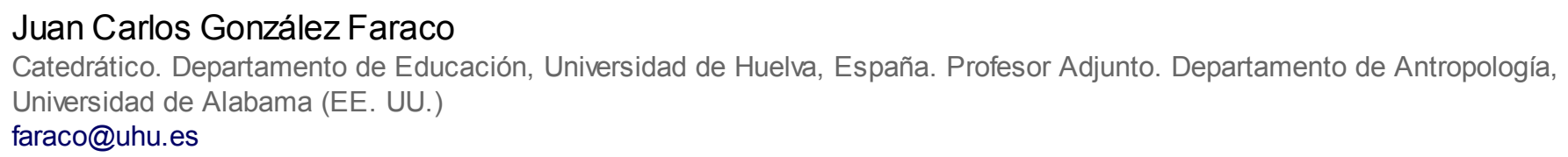

\begin{abstract}
RESUMEN
En este artículo queremos presentar y contextualizar la carta inédita de Gerald Brenan a su amigo Ralph Partridge, en la que describe su vívida experiencia de la romería del Rocío de 1958. Por una feliz coincidencia Brenan acudió al Rocío en uno de los años más cruciales de su larga historia, cuando se iniciaba el proceso de rápida expansión, más conocido por masificación, de esta famosa romería. La descripción de Brenan de este ritual andaluz por excelencia resulta doblemente interesante. De un lado, por la ausencia de buena parte de los elementos de una etnografía convencional, de los que sí se había valido en 'Al Sur de Granada', publicado un año antes. De otro, por el convincente y gozoso relato de su pasajero triunfo sobre las miserias del envejecimiento, una especie de fugaz liberación de sí mismo en este escenario ideal.
\end{abstract}

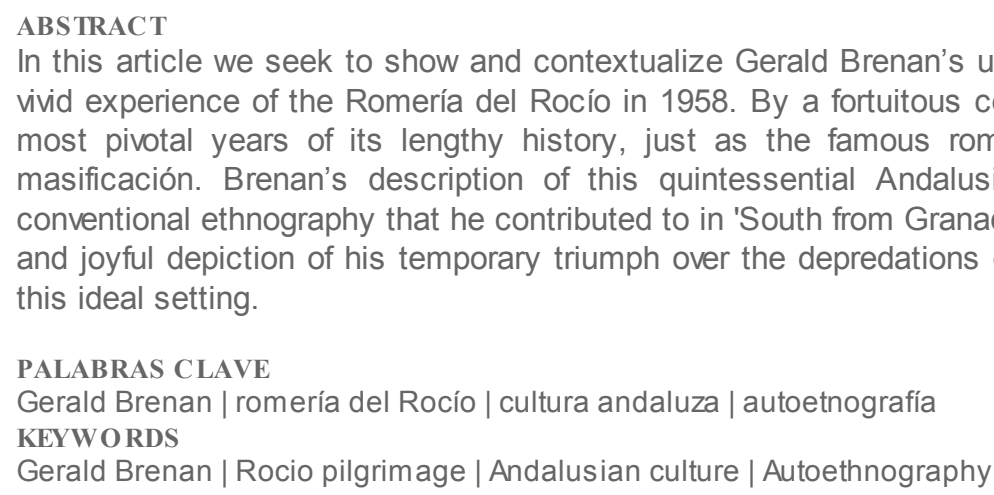
this ideal setting.

PALABRAS CLAVE

Gerald Brenan | romería del Rocío | cultura andaluza | autoetnografía

KEYWO RDS

Gerald Brenan | Rocio pilgrimage | Andalusian culture | Autoethnography

In this article we seek to show and contextualize Gerald Brenan's unpublished letter to his friend Ralph Partridge, describing his vivid experience of the Romería del Rocío in 1958. By a fortuitous coincidence Brenan participated in El Rocío during one of the most pivotal years of its lengthy history, just as the famous romería began the process of rapid expansion known as the masificación. Brenan's description of this quintessential Andalusia ritual is notable both for the absence of much of the conventional ethnography that he contributed to in 'South from Granada', published only a year before, as well as for its compelling and joyful depiction of his temporary triumph over the depredations of advancing age, a kind of fleeting liberation from his self in

\section{Introducción}

"En el Rocío todo el mundo encuentra lo que busca": eso fue lo que le oímos en cierta ocasión a una persona muy familiarizada con el mundo rociero. $Y$ algo así debió sucederle a Gerald Brenan, el distinguido hispanista británico, en la romería de 1958, a la que acudió acompañado de Gamel (1), su mujer, de sus amigos -la mayoría ingleses y norteamericanos- y de una joven llamada Hetty MacGee (2), cuya presencia fue clave para él. Lo sabemos porque sólo dos días después de finalizar la romería, ya de vuelta en su casa de Churriana, Málaga, le escribió una larga carta (3) a su íntimo amigo Ralph Partridge (4) que empieza de este modo: "Y ahora debo realmente sentarme y escribirte mis impresiones sobre la romería de la Virgen del Rocío, en la que he pasado cuatro de los más felices y deliciosos días de mi vida" (5). Y en la que algo más adelante dice: "No, nunca me olvidaré del Rocío mientras viva: su asombrosa belleza y su alegría, lo más maravilloso que he visto en mi vida".

Por una feliz coincidencia, este inglés, tan conocedor y amante de Andalucía (6), visitó por primera vez la romería del Rocío en un año crítico de su historia contemporánea. Hasta entonces, para ir desde el pueblo onubense de Almonte a su aldea del Rocío había que recorrer un camino arenoso de unas tres leguas, que discurría entre bosques de pinos y eucaliptos y de matorrales. Poco antes de la celebración de la romería de ese año, se había abierto al tráfico una carretera empedrada, todavía sin asfaltar, pero practicable para automóviles convencionales. Según algunos datos disponibles (Álvarez Gastón 1981: 110), el volumen de 
romeros que acudió al Rocío dobló al del año precedente (de 30 a 60 mil, sin contar con la llegada de muchos vehículos a motor) (7). Comenzaría así un veloz y complejo proceso de crecimiento y masificación, muy relacionado con la "explosión turística" que se iniciaría en la zona en la década inmediata (Ojeda 1987: 333, Murphy y González Faraco 1996). Desde entonces, la cifra de asistentes a la romería seguiría aumentando, con aceleración sostenida, hasta alcanzar el millón en 1980. También el número de hermandades, que en 1958 era de treinta, seguiría una pauta similar hasta sobrepasar ampliamente el centenar en la actualidad, extendiéndose significativamente el "territorio de gracia" (Christian 1972) de esta devoción mucho más allá de su ámbito geográfico original, la Baja Andalucía. El Rocío llegaría a convertirse en uno de los símbolos mayores de esta región (Rodríguez Becerra 1989, Martínez Moreno 1997), la romería más famosa y masiva de toda la Península lbérica y también una de las grandes devociones marianas de la Europa católica (Murphy y González Faraco 2013).

Si hiciéramos un ejercicio de retrospectiva, se podría apreciar en su justa medida la crucial importancia (8) que tendría de cara al futuro la construcción en 1958 de una carretera entre Almonte y el Rocío. En ese momento, sin embargo, los cambios aún no habían comenzado, ni siquiera se vislumbraban. Y la Aldea del Rocío seguía ofreciendo una imagen no muy diferente a la que recogió treinta años antes el periodista del diario El Sol, Luis Bello, en su Viaje por las escuelas de Andalucía: "iTierra singular, paradisíaca, primitiva, imposible sobre cualquier otro rincón de Europa!” (Bello 1998 [1928]: 267). Lo que Brenan contempló era todavía un lugar apartado en medio de la esplendorosa naturaleza de las marismas del Guadalquivir y el coto de Doñana, despoblado y sin los más básicos recursos modernos, como la luz eléctrica. Un lugar solitario que una vez al año, por Pentecostés, era invadido por la alegre algarabía de los romeros y la fiesta. En su carta a Partridge quedan de manifiesto estas características distintivas de la Aldea, pero además en ella da cuenta, con expresivo estilo, de las impresiones que la romería (su ambiente, sus ritos más sobresalientes) le produjo a alguien que se acercaba al Rocío por primera vez, tal vez con los ojos ingenuos de un extranjero que, no obstante, tenía un estrecho vínculo con la cultura andaluza, especialmente con la de Andalucía oriental, adonde había llegado en 1919.

Entre otras muchas cosas, Brenan era, como ha dicho muy acertadamente su biógrafo Gathorne-Hardy (1992), un escritor dado a escribir largas cartas muy pensadas, y ésta es, desde luego, una prueba elocuente de su estilo epistolar. Además de dar a conocer el manuscrito en inglés, hasta ahora inédito, y su traducción al español (traducir cualquier texto es siempre aventurado, cuánto más uno con estas características), procederemos al análisis de su contenido, aunque sin olvidar sus cualidades formales. Para ello, observaremos la carta como si fuera una representación teatral, con su escenario, actores y argumento. Finalmente, propondremos algunas conclusiones sobre su interés etnográfico, aunque no se trate, en absoluto, de un texto deliberadamente etnográfico.

\section{Gerald Brenan, escritor epistolar}

El 24 de mayo de 1958, Brenan llegó al Rocío desde Sevilla con una singular comitiva de españoles, ingleses, americanos y gibraltareños, que se distribuyó por distintos lugares y alojamientos de la Aldea, y allí pasó los tres días de la romería. La carta que presentamos y estudiamos, recoge algunos detalles de lo que pudo observar durante esa estancia, pero, sobre todo, sus vivencias personales, tan intensas y gozosas como acaso fugaces.

Era de suponer, ateniéndonos al contenido exultante de esta carta, que Brenan hubiera dedicado algún recuerdo a esta su primera visita al Rocío en alguno de sus voluminosos textos autobiográficos, pero no hay el menor rastro de esta experiencia, tan aparentemente extraordinaria para él, en ninguno de ellos. Es cierto que el relato de su segunda etapa en Churriana, que duró nada menos que 17 años, se reduce a un capítulo de pocas páginas de Personal Record (1975), una autobiografía de Brenan que va desde 1920 hasta 1972. Tampoco Xan Fielding (1986) escogió esta carta para su edición selectiva de la abundante correspondencia entre Brenan y Partridge, titulada Best of Friends, y publicada de acuerdo con el propio Brenan en 1986, un año antes de su muerte. Debemos el conocimiento, casual e inesperado, de la existencia de esta carta (véase la nota 3) a la comprensiva biografía de Jonathan Gathorne-Hardy (1992: 449-450), quien incluye un comentario y una cita literal en el capítulo que dedica a Hetty.

Además de esta colección editada por Fielding, disponemos de otra que recoge la correspondencia entre Gerald Brenan y Julio Caro Baroja, publicada por Carmen Caro Jaureguialzo (2005). Gathorne-Hardy (1992: 
426) asegura que Julio Caro Baroja fue uno de los dos únicos amigos íntimos españoles que tuvo Brenan (9). Sin embargo, al cotejar ambas colecciones de cartas se aprecia una nítida diferencia en cuanto al grado y tipo de amistad que Brenan cultivó con Partridge y con Caro Baroja respectivamente, eso sin contar con que este último está completamente ausente de Personal Record. Incluso una lectura superficial de la correspondencia entre Brenan y Partridge recogida por Xan Fielding, permite apreciar la sinceridad con la que ambos se expresaban al contarse sus respectivas experiencias románticas y sexuales, fueran reales o imaginarias. Resulta particularmente reveladora la comparación de la carta objeto de este artículo con la que Brenan remitió a Caro Baroja sobre su segunda visita al Rocío en 1968 (Caro 2005: 142-143). Por supuesto, la situación personal de Brenan había cambiado drásticamente en esos últimos diez años. Su mujer, Gamel, había muerto hacía pocos meses y él estaba viviendo con otra joven inglesa, Lynda Nicholson. Su envejecimiento era cada vez más palpable y, por si fuera poco, esta segunda experiencia rociera, según nos cuenta Gathorne-Hardy (1992: 517), no le fue tan grata como la primera. Pero lo que nos interesa señalar es que la carta de Brenan a Caro es breve, descriptiva, formal. Todo indica que su grado de confianza personal era sensiblemente menor que el que había entre Brenan y Partridge. De hecho, Fielding (1986: 3), que habla con conocimiento de causa, los describe como amigos muy cercanos durante cuarenta y cinco años, y Malpartida (2006: 56), de forma igualmente convincente, no cree, a diferencia de GathorneHardy, que la relación entre Caro Baroja y Brenan fuera la de "una amistad intima". En cualquier caso, baste simplemente con reconocer que hay diferentes tipos y grados de "amistad íntima" y que la que había entre Brenan y Caro Baroja era de naturaleza distinta a la que por más de cuatro décadas había unido a Ralph Partridge y Gerald Brenan, cuando éste le remitió una carta contándole su primera visita al Rocío.

Sin lugar a dudas, Gathorne-Hardy (1992: 563) es el mejor conocedor de la imponente correspondencia (10) de Brenan, de la que estas dos colecciones, las únicas hasta ahora publicadas, no recogen más que una ínfima parte. Brenan fue un escritor epistolar profuso. Gathorne-Hardy (1992: 413) está incluso convencido de que, a partir de un cierto momento, Brenan consideró que escribir cartas era parte de su trabajo, y no una simple digresión, paralela o tangencial a su obra. De hecho, la lectura de esta carta sobre su visita al Rocío revela claramente que no fue fruto de la improvisación sino de un cierto plan narrativo, como se advierte a través de su estructura y su cuidada escritura. La ilusión de toda su vida fue llegar a ser poeta y novelista, pero seguramente no será recordado ni por su poesía ni por sus novelas, pero acaso sí por sus memorias, ensayos literarios, históricos y etnográficos, y por sus cartas (11). No es casual que Gathorne-Hardy (1992: 610) cierre su biografía con estas palabras: "Es posible que su ingente correspondencia termine por ser a la sazón el recuerdo más duradero de Gerald" (12).

Esta carta, como otras muchas que escribió Brenan, es un largo texto de diez páginas manuscritas, con una organización narrativa cronológica que abarca el periodo de cuatro días que va del 24 al 27 de mayo de 1958. Es la crónica de un viaje de ida y vuelta a su residencia de Churriana con un destino y un motivo central: la romería que se celebra en la lejana Aldea del Rocío, a orillas de las marismas del Guadalquivir, entre la tarde del sábado y la del lunes de Pentecostés. Los sucesos descritos están ordenados en periodos que se refieren a su estancia en la acampada o en la casa de sus amigos de la Cónsula, o bien a sus salidas con Hetty a las calles de la Aldea; en ambos casos, como pequeños viajes, también de ida y vuelta, al punto de partida. Y siempre, de fondo, el entorno bullicioso de la romería. Para Brenan, la romería del Rocío, mucho más que una celebración socio-religiosa que describir, representó un contexto ideal en el que podía experimentar, y contar, la alegría del triunfo, aunque fuera transitorio, sobre el deprimente proceso de envejecer.

Brenan escribe su relato "en caliente", el 29 de mayo, solo dos días después de haber regresado del Rocío. Sin embargo, no lo hace de manera desaliñada o improvisada, exclusivamente impulsado por el deseo de compartir con Ralph sus vivencias y emociones, sino siguiendo una pauta narrativa prevista y muy preocupado por el estilo, como se deduce del empleo de un léxico visiblemente escogido, numerosas expresiones estéticas, frecuentes metáforas y algunas referencias cultas. Prueba asimismo de este esmero son las correcciones que salpican el manuscrito. Resulta, al fin, una descripción muy literaria del ambiente de la romería y de la Aldea. Sin embargo, no conviene olvidar que estamos ante una carta dirigida a un viejo amigo, al que Brenan podía dirigirse con entera libertad, sin verse condicionado por la posible respuesta del destinatario y, por tanto, sin tener que recurrir a la discreción, al comedimiento o a la cautela que debía tener presentes con quienes, como Caro Baroja, no compartía ese grado de complicidad. 


\section{Gerald Brenan, un inglés en el Rocío}

Brenan no fue ni pretendió ser nunca un antropólogo (13); fue, a la manera de los más importantes viajeros ingleses románticos, de los que quizás fue el último (14), un observador sagaz de la cultura española, que estudió y amó, pero sin involucrarse socialmente en ella. "Gerald -escribe Gathorne-Hardy (1992: 593)- no era ni remotamente español. Era extremadamente inglés y era muy de su tiempo y de su clase social. Nunca se paró a pensar siquiera en la posibilidad de nacionalizarse". Brenan mantuvo toda su vida una "despegada relación con España" (Lozano 1984: 186), relacionándose casi exclusivamente con un limitado círculo de extranjeros de habla inglesa, que eran sus vecinos o lo visitaban de vez en cuando (GathorneHardy 1992: 292). En Churriana, donde residió largas temporadas entre 1934 y 1970, formó parte de una nutrida colonia de expatriados, cuyo centro de gravedad era la Cónsula, una especie de mansión propiedad de los norteamericanos Bill y Anne Davis, en la que eran frecuentes las reuniones sociales y literarias, y la presencia de visitantes de alto relieve internacional, como Orson Welles, Ernest Hemingway, Bertrand Russell, David Niven, y un largo etcétera de celebridades.

Pero Brenan no fue, a diferencia de la mayoría de los viajeros ingleses, un visitante ocasional de Andalucía. Desde su llegada a las Alpujarras, en enero de 1920, hasta su muerte en Alhaurín El Grande, en enero de 1987, vivió en Andalucía un total de cuarenta años (Gibson 1984: 178), si bien con frecuentes y prolongadas ausencias.

Brenan no fue el primer extranjero (ni sería el último) en visitar el Rocío y dejar constancia escrita de sus observaciones. Por lo que cuenta, cabe suponer que llegó allí con una cierta información previa, aunque exigua. Desde luego, estaba familiarizado con las obras sobre España de Richard Ford y George Borrow, y puede que conociera los textos sobre el Rocío del francés Antoine de Latour (1858), o de los ingleses Abel Chapman y Walter Buck (1910), pero no parece lo más probable. Su conocimiento del Rocío era, en todo caso, muy limitado, pero seguramente estaba al tanto, quizás por su conocimiento de otras romerías andaluzas o por la notable popularidad de ésta en particular, de que se trataba de una fiesta propicia para la relajación moral.

Quizás la mayor diferencia entre la experiencia rociera de Brenan y la de esos otros visitantes extranjeros radica en que él viajó al Rocío con el deseo y el objetivo primordial de su propia participación en la fiesta. Tanto es así que ese es precisamente el tema en torno al cual gira toda su carta a su amigo Partridge. Pero antes de comenzar a recrear su contenido, es decir, a analizar la visión que Brenan nos transmite del Rocío, vamos a esbozar su contexto: el Rocío de mitad del siglo XX en el marco de su centenaria historia.

\subsection{EI Rocío y su romería}

En 1958, la Aldea del Rocío tenía alrededor de 300 vecinos pertenecientes a unas 80 familias, la mayoría de ellas originarias de unos pocos municipios próximos, principalmente del de Almonte (15). Residían en un conjunto desordenado de casas y chozas, agrupadas en pocas calles y descampados de irregular trazado en torno a la ermita de la Virgen, construida a mediados del siglo XVIII, en el mismo solar que hubo ocupado hasta entonces la primitiva, seriamente dañada por el terremoto de Lisboa en 1755. Esta primera y mínima ermita fue levantada, como otras tantas en esa región, tras la reconquista del reino de Niebla por Alfonso $X$ a finales del siglo XIII. Una descripción de la primera mitad del siglo XIV, en el Libro de la Montería atribuido a Alfonso $\mathrm{Xl}$, ofrece un retrato muy plástico de esta tierra, salvaje, insana, inhóspita y aislada, conocida entonces como Las Rocinas. La pequeña imagen gótica de la Virgen María, alojada en la ermita, adoptaría ese nombre, Nuestra Señora de las Rocinas, hasta trocarlo por el de Rocío en la primera mitad del siglo XVII, dando nombre a su vez al lugar y al caserío que había ido creciendo alrededor.

A mitad del siglo XIX, según el relato de Antoine de Latour (1858), el Rocío y la llanura que lo circunda, seguían siendo un desierto demográfico, solo alterado brevemente durante la romería de Pentecostés, que con el tiempo fue ampliando su duración original hasta los tres días centrales que tenía en 1958 y que tiene aún hoy, aunque con algunas variaciones.

El sábado (16), víspera de Pentecostés, tiene lugar la entrada y recepción oficial de las hermandades filiales por la Hermandad Matriz de Almonte: un desfile ordenado, según su antigüedad, de cada una de ellas con su carreta, en la que se transporta y se venera su estandarte o simpecado. Esta especie de baldaquino rodante, tirado por bueyes o por mulos, suele ir precedido por jinetes a caballo, vestidos a la usanza andaluza, y seguido por romeros a pie, carros y carretas en los que muchos de ellos han "hecho el camino" 
desde su localidad de procedencia. Llegada la noche se celebra un rosario, exclusivo de la Hermandad de Almonte, que recorre Real de la Aldea.

El domingo, día de Pentecostés, el acto religioso central es una misa solemne, que se celebra en El Real, en el lugar donde se levanta un monumento alusivo a la coronación de la Virgen del Rocío en 1919. A esta misa, acuden las representaciones oficiales de las hermandades con sus simpecados. En la ermita, atestada de público, la gente entra y sale, reza, grita aclamando a la virgen, canta, curiosea, conversa, mientras bajo sus pies la arena va cubriendo la solería hasta casi hacerla desaparecer a la vista. La fiesta, en las calles, en las viviendas particulares, en las casas de las hermandades, está en su apogeo. El día termina y da paso a la madrugada con un nuevo rito masivo en el que toman parte todas las hermandades: un rosario cantado. Una doble hilera de romeros con velas encendidas precede a cada simpecado, alumbrado a su vez por bengalas de colores.

La "procesión del lunes", como se la suele conocer, es el rito más conocido y espectacular de la romería del Rocío. A finales de los cincuenta se iniciaba a primeras horas la mañana, tras una sucesión de misas previas. Una vez en la calle, la Imagen, llevada hombros por los almonteños, deambula entre una multitud enardecida por un itinerario irregular que circunda en parte la ermita. Una marea humana sigue de cerca los movimientos erráticos del paso, que se inclina, cae, se levanta, y va de aquí para allá, como un oleaje, al encuentro de cada uno de los simpecados que jalonan el recorrido. Se producen escenas vibrantes y emotivas: se dicen vivas, se corean salves que un cura reza a compás, batiendo compulsivamente los brazos... Mientras, la bulla y la confusión no cesan, sobre todo en las inmediaciones de y bajo las andas, donde, a un tiempo, se funden los empujones, los rezos, las aclamaciones fervorosas, los abrazos emocionados, los llantos, el vocerío, las disputas y las riñas, a veces violentas. De vez en cuando alguien aparece exhausto, sudoroso, renqueante... Los niños vuelan sobre las cabezas para que rocen, con su cuerpo o con sus manos, el manto milagroso de la Imagen... Puede decirse que el fin de la procesión significa el fin de la romería en la Aldea del Rocío y la señal que anuncia el inminente regreso de las hermandades a sus pueblos y ciudades.

Aunque se trate obviamente de una devoción religiosa católica basada en un entramado de hermandades, como tantas otras en Andalucía (Rodríguez Becerra 2005: 42-50), el Rocío, por su trayectoria histórica específica, constituye un modelo característico, extraordinariamente influyente, y por ello imitado en el mundo de las devociones marianas andaluzas y, desde luego, sumamente peculiar en el de las grandes devociones de la Europa católica, entre las que se cuenta (Murphy y González Faraco 2013).

El éxito de la romería del Rocío y su vertiginoso crecimiento a partir de la década de 1960, fruto de una compleja y feliz confabulación de factores diversos, han dado lugar a un conjunto de cambios que, en 1958, eran solo incipientes. Ya hemos insistido en ello: en 1958 el Rocío se encontraba en los umbrales del proceso de masificación, cuya primera y más visible señal fue la carretera desde Almonte recién trazada y, aunque toscamente, ya pavimentada. Su existencia atrajo a numerosos visitantes, e hizo posible el viaje de Brenan y sus acompañantes en un tiempo y en unas condiciones aceptables, a una aldea remota, premoderna, a un "center out there" (Turner 1973), al que solo podía llegarse, hasta ese año, por caminos de arena impracticables para un turismo. Ese aislamiento no había impedido, sin embargo, que la romería del Rocío se convirtiera, fundamentalmente a partir del siglo XIX, en una fiesta extraordinariamente popular en la Baja Andalucía, recreada por escritores costumbristas y románticos, principalmente de Sevilla, hasta el punto de formar parte de la oferta "turística" sevillana en la Exposición lberoamericana de 1929 (Padilla 2010: 217-224).

Ya en esos momentos, también desde mucho tiempo antes (Adame y Muñoz 1849; Latour 1858), el Rocío reunía la doble condición de devoción y fiesta de una comunidad, Almonte, en honor a su patrona, y a la par de un ramillete de comunidades perimarismeñas a las que en 1813 se unió la ciudad de Sevilla a través de la Hermandad de Triana. Es decir, una devoción estrechamente unida "a" y protagonizada por la comunidad local, y al mismo tiempo una devoción supralocal que, con el proceso de masificación, alcanzaría la escala regional e incluso nacional a través de la emigración andaluza a Madrid y Barcelona, principalmente (Jiménez de Madariaga 1997, Padilla 2010). Es insólito, o al menos infrecuente, en devociones católicas de este rango que escalas tan dispares sigan coexistiendo en un cierto equilibrio sujeto, desde luego, a tensiones periódicas. Y lo más sorprendente: que, a pesar de la dimensión alcanzada por el Rocío, el control de la romería y los rituales que en ella se desarrollan, de la ermita y de la aldea, siga básicamente en manos de instituciones locales, la Hermandad Matriz y el Ayuntamiento de Almonte, que, no sin conflicto entre ellas, resisten como pueden las acometidas e intromisiones de agentes externos como, por ejemplo, las de la 
jerarquía de la Iglesia católica.

\subsection{Una experiencia rociera particular}

Vayamos ahora al Rocío contemplado y vivido por Gerald Brenan, y en consecuencia al rito (al espacio, al tiempo y al ambiente ritual), como acontecimiento puramente subjetivo. Desde las primeras frases de la carta de Brenan a Partridge queda meridianamente claro que está escrita no para darle cuenta a su destinatario de sus observaciones del Rocío, sino de sus experiencias personales, básicamente con Hetty, uno de los tres personajes centrales de esta historia junto al propio Brenan y su esposa Gamel. A este trío habría que sumar el resto de la comitiva con la que se desplazaron desde Málaga al Rocío, vinculada en su mayor parte a la Cónsula y sus propietarios, los norteamericanos Bill y Annie Davies. En este grupo conviene destacar, no obstante, a Katie Murchie, promotora, junto a su marido Guy, de esta excursión o esta farsa, según se la mire.

Brenan insistió desde el principio en ir acompañado de Hetty, una joven de 31 años, a la que acababa de conocer y a la que, por cierto, doblaba la edad. De hecho, lo puso como condición para unirse al viaje (Murchie 1995: 342), lo que a Katie Murchie disgustó sobremanera, entre otras razones por resultarle inadmisible el desaire que la presencia de Hetty suponía para Gamel, quien de hecho se vio relegada a un segundo plano. Hetty, sin embargo, estaba muy por debajo de Gamel en muchos aspectos muy valorados por Brenan a lo largo de toda su vida (la clase social, el nivel cultural, la educación...), pero esta joven, dada a las drogas y a las aventuras bohemias en la costa malagueña (Gathorne-Hardy 1992: 447-472), representaba, con su "cara de muñeca", la juventud, la vitalidad, el descaro, la pasión... Con Hetty, a través de Hetty, Brenan participa en la romería, y se sumerge en su ambiente dionisíaco. Con Gamel, con quien pasa mucho menos tiempo, se limita a observar lo que acaece a su alrededor.

En su autobiografía Personal Record no encontramos ni una sola mención a estos días tan supuestamente especiales que compartieron Brenan y Hetty en el Rocío. Esta tuvo una importancia muy relativa y, sin duda, pasajera en su vida, pero en aquel preciso momento, cuando además, según Gathorne-Hardy (1992: 419), su relación con Gamel estaba debilitándose, Brenan debió pensar que ese viaje podía ser una magnífica ocasión para estar con esta joven tan sensual en un ambiente distendido, incluso en presencia de su mujer. En realidad, Hetty fue tan solo un instrumento, un vehículo, para su participación en el Rocío.

Brenan tenía muy desarrollado el sentido del ridículo, pero lo perdía por completo cuando se acercaba o estaba con chicas mucho más jóvenes que él. Por supuesto, a los demás (a Katie Murchie, en particular) les parecía fuera de lugar, e incluso grotesca, esta afición a las jovencitas (que, por cierto, lo acompañó toda su vida) en un hombre de su edad, más que sexagenario. Sin embargo, su respuesta a tal tipo de críticas o censuras fue contundente: no iba a prestarles la menor atención, pues estaba decidido a disfrutar de la vida sin la menor restricción. Una pretensión bastante ajena a su vida real, en la que el deseo sexual se vio frecuentemente contenido o frustrado. Incluso en sus relaciones con Hetty, tan vehementemente vivida, esta contención es más que evidente. Se trataba, pues, de una especie de manifiesto a favor del gozo sin tapujos (la cita final de Arthur Rimbaud no es casual), poco verosímil y más bien literario, pero dirigido a la persona que quizás podría entenderlo mejor, su gran amigo Ralph.

La lucha contra el envejecimiento era, según Gathorne-Hardy (1992: 425), una cuestión recurrente en la correspondencia de esa época. En esta carta es más que patente. El Rocío se convirtió, a sus ojos, en un sitio ideal donde hallar esa sensualidad libre de toda atadura, que había perseguido toda su vida sin demasiado éxito, y tal vez frenar y quién sabe si también invertir el sentido de una decadencia que tanto lo turbaba. Brenan no acude al Rocío con el espíritu de un espectador, ávido de exotismos culturales, sino como quien quiere vencer las penurias del envejecimiento y, con ello, la tragedia de la mortalidad; cosas que, como la precariedad económica o el sexo, le obsesionaron siempre, principalmente en su vejez. En uno de los párrafos más vigorosos de su carta leemos: "Everywhere we went, clap clapping of hands, rattle of castanets, voices singing, and whirl of bodies. We were annihilating time; we were drowning it with our gaiety". "Aniquilando el tiempo, ahogándolo en nuestra alegría..." Es esto lo que Brenan extrae, sobre todo, del Rocío, ese es su Rocío: un lugar en el que el tiempo se esfuma y con él la miserable vejez.

\subsection{La romería de Brenan}

Brenan llegó al Rocío ligero de equipaje intelectual, sin más pretensión que aprovechar a fondo esos días de asueto y diversión. Estaba, desde luego, familiarizado con la cultura andaluza y con sus manifestaciones 
religiosas populares, pero no parece que tuviera conocimiento alguno de la historia ni de los aspectos culturales y rituales de esta romería en particular. Sin embargo, por lo que se trasluce de su carta, cabe deducir que se embarcó en este viaje con una cierta información previa, tal vez extraída de la lectura de los textos de otros viajeros ilustres y a sabiendas de que se trataba de una romería muy famosa, extraordinariamente festiva y laxa. Por supuesto, llegaba al Rocío con la experiencia vital de muchos años en Andalucía y las lecturas acumuladas durante décadas sobre la cultura y, especialmente, sobre la literatura española (López López y Muñoz Palomares 1992). Un año antes de este viaje había publicado South from Granada, un libro en el que Brenan presentaba un relato bastante meticuloso de la vida en Yegen, el pueblo alpujarreño en el que residió, con frecuentes interrupciones, entre 1920 y 1934. Su texto tiene una organización solo ligeramente sistemática de sus recuerdos y se basa en una cierta pesquisa que lleva a cabo con toda intencionalidad, hasta el punto de volver a Yegen muchos años después para cerciorarse bien de los hechos que recordaba. A su manera, muy a su manera (17), Brenan se había inspirado en The People of the Sierra, una obra etnográfica que admiraba y que había sido publicada pocos años antes (1954) por su amigo Julian Pitt-Rivers, quien, más de una vez, había encomiado las cualidades de Brenan como observador. Al Rocío fue, sin embargo, para divertirse tanto como pudiera, y no para observar y dar cuenta de los hechos observados en un informe más o menos exhaustivo.

Sin embargo, esta carta manuscrita, a pesar de su relativa brevedad, contiene muchas y variadas riquezas. Ante ella como ante cualquier texto, sea cual sea su naturaleza, conviene considerar y examinar al mismo tiempo no sólo lo que dice explícitamente, sino también lo que queda en un segundo plano y lo que se calla. Lo ausente, como es bien sabido, puede tener un gran interés etnográfico. Pensemos, por ejemplo, en el papel de la mujer en las descripciones de Malinowski de la cultura trobriandesa. En el relato de Brenan encontramos referencias pormenorizadas de ciertos acontecimientos e impresiones, y también sonoras ausencias. Sus observaciones son muy selectivas. No puso el menor interés en los aspectos religiosos del Rocío, y solo muy de pasada (quizás con la excepción de la procesión del lunes) se detuvo en los rituales más sobresalientes que describe con pocas palabras, sin apenas detalles y llamándolos "procesiones" indistintamente. No menciona a Almonte ni a los "almonteños" que en esa época ya tenían un notorio papel protagonista en la romería, ni parece que se interesara por saber algo más sobre el Rocío. De hecho, no hay evidencia de que hiciera preguntas o se informara a través de otras personas. Puede incluso que no entrara en el santuario ni una sola vez durante su estancia en la Aldea. No hay, en fin, la menor alusión al significado cultural o histórico del Rocío y los datos propiamente etnográficos son escasos, cuando no erróneos.

A pesar de ello, la carta tiene la virtud de captar y recrear con extrema expresividad y finura los aspectos más característicos del ambiente rociero: los sonidos que se oyen por doquier (cantes, palmas, castañuelas, cohetes), el abigarrado movimiento de los caballos y los carros, la extraña sensación de la arena cubriendo las calles, el aire envuelto en nubes de polvo, las curiosas gradaciones de la luz a distintas horas del día, la profunda oscuridad de la noche salpicada de candelas, el trajín festivo en la puerta de casas y chozas (el baile, el flirteo, la bebida), el tumulto, el bullicio, las acampadas... Todo ello pintado con una calculada reiteración de palabras e imágenes, típica de su estilo. En su manuscrito, Brenan muestra también su destreza para retratar, con pocos trazos, los muy diversos ambientes sociales presentes en la romería, a algunos de los cuales puede acceder a través de sus amigos de la Cónsula. En todo caso, su descripción es impresionista, somera, fragmentaria. Se siente mucho más atraído por la vida en la calle que por las reuniones de la buena sociedad en el interior de las casas. Cree descubrir en el Rocío las reminiscencias de una bacanal, de un ritual dionisíaco antiguo en el que la sensualidad está a flor de piel. Su visión, dominada por cuanto guarda relación con los sentidos y la emoción, está poblada de sonidos, imágenes, sensaciones físicas, excitación erótica, y pasa de puntillas o sencillamente deja al margen los actos rituales, las celebraciones colectivas, los hechos que, por el contrario, suele relatar la mayor parte de los observadores, nativos o foráneos, de la romería del Rocío, a veces con la intención de hallar un principio o una categoría histórica o antropológica más o menos holística o universal. En cualquier caso, y a pesar de su notorio egocentrismo, criticado entre otros (18) por McCormick (2008: 91), la ensimismada reflexión de Brenan sobre su experiencia en el Rocío nos ofrece, no obstante, una expresiva descripción de algunos de los aspectos de su tan afamado ambiente.

\section{A modo de conclusión: la peculiar "etnografía" de Gerald Brenan}

Gracias a sus cualidades para la observación, por las que era bien conocido en su propio entorno, y a su 
estrecha vinculación con Andalucía, Brenan fue un observador singularmente agudo de la cultura andaluza. Sin embargo, quizás salvo en este caso, su observación nunca fue "participante", o lo fue tan sólo en el sentido de que él solía ser siempre el protagonista. Su visita al Rocío constituye, en cierto modo, una llamativa excepción en esa actitud vital generalmente espectadora, con frecuencia fabuladora, y en cierto modo distante de la vida social española. En El Rocío, Brenan se sumergió literalmente en el ambiente de la romería, pero solo prestó atención y tomó parte en aquello que le pudiera proporcionar entusiasmo y disfrute. En South from Granada, como acabamos de comentar, Brenan había buscado una cierta impronta etnográfica, pero en realidad solo mostraba una cadena de anécdotas, una serie de ensayos yuxtapuestos, brillantemente escritos. En su texto manuscrito sobre el Rocío no hay, en cambio, el menor empeño en producir esa "ilusión etnográfica", y no sólo porque fuera una misiva personal dirigida a un amigo, sino porque su punto de vista y su móvil son otros: vivir con todas sus consecuencias una experiencia liberadora del envejecimiento.

Brenan, como es obvio, no se condujo en absoluto como un etnógrafo "convencional". No se ocupó de escudriñar con detenimiento lo que sucedía a su alrededor, ni parece que hiciera preguntas sobre las creencias o los ritos que se desarrollaban ante sus ojos, ni que registrara sus observaciones con el rigor, la minuciosidad y la distancia exigidos por el método etnográfico de su tiempo. Entonces, el "yo" era el gran ausente en los textos etnográficos comunes. El etnógrafo (pensemos en Evans-Pritchard, de nuevo en PittRivers) trataba de evitar por todos los medios su protagonismo en la investigación, sometiéndola a un método exigente, recabando y contrastando prolijamente los datos, alejándose de su objeto de estudio y, en suma, intentando limitar al máximo el impacto de su subjetividad. Brenan toma justo el camino opuesto y dirige su mirada principalmente hacia sí mismo y hacia su acompañante, la alocada Hetty, y también, aunque menos, hacia su esposa Gamel y demás compañeros de viaje. De algún modo y, desde luego, sin pretenderlo, se adelanta a lo que hoy es corriente: que el antropólogo y su subjetividad jueguen un papel esencial en la investigación antropológica. Su carta viene a ser, por eso, como una "autoetnografía" o una etnografía a la busca de sí mismo, que es la expresión usada por Lisón Tolosana (2011: 12) para describir la "actitud etnográfica" de Brenan.

Esta "etnografía de sí mismo", por llamarla de algún modo, tiene mucho de literaria, como la vida de Brenan en su conjunto, o de egotismo literario, si se quiere. Brenan pasó su larga vida, que siempre imaginó, no sin cierta teatralidad, mucho más corta de lo que realmente fue, entre libros y entre extranjeros, mayormente ingleses, que con frecuencia hablaban de libros. Su experiencia vital en Andalucía no fue la de un viajero ocasional, pero tampoco la de un etnógrafo tradicional, ni siquiera, salvo en contados casos, la de un etnógrafo amateur, ni mucho menos la de un erudito: fue una experiencia literaria caracterizada, acaso, por un cierto quijotismo poco dado a aventuras reales, un quijotismo más bien imaginario y contenido. En su carta se aprecia con claridad, incluso bajo el hechizo y el arrebato de esta experiencia en El Rocío, su incapacidad de zafarse de la literatura como mundo y referencia vital. Entre caballos airosos, bueyes pomposos, procesiones pintorescas, música y tragos de vino, y ensoñaciones eróticas, parecen deambular Cervantes y Góngora, Robert Louis Stevenson y Rimbaud, alimentando la fabulación de Brenan en relación con las mujeres, el sexo o la vejez. Su relato sugiere una obra teatral romántica en la que la Aldea es el escenario magnífico en el que intentar vencer el paso del tiempo y ganarle así la partida a las desdichas del envejecimiento. Culmina su narración en un canto a la vida desatada de toda constricción que alcanza su paroxismo con el poema de Rimbaud, un personaje cuyo arrojo y desmesura distan mucho de la contradictoria personalidad de Brenan. Pero su carta de es mucho más que una mera ilusión literaria, bellamente tejida; es también la expresión candente de una experiencia vivida, corporeizada, es decir, la encarnación de esa experiencia en un sujeto, pues convoca a todos sus sentidos bajo un aluvión de sonidos, olores, colores y formas, a los que Brenan dedica muchas y brillantes alusiones.

Comenzamos este artículo diciendo que cada cual encuentra en el Rocío lo que busca, que es una manera de decir que el Rocío, como todo fenómeno cultural complejo, tiene innumerables lecturas. Sin embargo, a lo largo de su dilata historia, pero especialmente desde que esta romería andaluza ha cosechado tanto éxito y fama, suele ser objeto de disenso y provocar lecturas antagónicas, como resulta común con otros hechos o aspectos relevantes de la cultura andaluza y de la cultura española en general. Los defensores a ultranza, de un lado; los detractores, del otro. Gerald Brenan no entra en esta pugna, ni se plantea lo que pueda significar el Rocío en general, conceptual o ideológicamente considerado. Tan solo lo que ha significado para él, la gozosa emoción que le ha procurado. Por eso decimos que este manuscrito de Brenan es una especie de "etnografía de si" y también una "etnografía del gozo". Como antes insinuamos, incluso podríamos verlo como un precedente de una cierta perspectiva posmoderna de la antropología y, en este sentido, como un 
anticipo de ese componente narcisista tan presente en ciertos antropólogos contemporáneos que hacen de la etnografía una narración de sí mismos.

\title{
Anexo I: Carta (19) de Gerald Brenan a Ralph Partridge
}

Churriana, 21 de Mayo, 1958

\author{
Querido Ralph (20),
}

Y ahora debo realmente sentarme y escribirte mis impresiones sobre la Romería de la Virgen del Rocío, en la que he pasado cuatro de los más felices y deliciosos días de mi vida.

Salimos con los Murchies (21) el sábado por la mañana, llegamos a Sevilla a las cuatro y un par de horas después al Rocío. Imagina un gran llano arenoso, en parte cubierto de pinos piñoneros y eucaliptos, y dando a Las Marismas. Imagina un conjunto desordenado de chozas y casas de una planta repartidas por anchas y arenosas calles y plazas, completamente vacío y desértico excepto durante estos días del año. Y ahora imagina 12.000 hombres, mujeres y niños, 1000 caballos, 300 carretas (22) tiradas por bueyes e incontables mulos y burros. Al moverse por las calles levantan en el aire nubes de polvo y arena. Y por todas partes resuenan palmas, sonido de castañuelas y coplas flamencas.

Llegamos justo cuando se estaba formando la procesión (23) en torno a la ermita de la Virgen. Consistía en un largo desfile de carretas adornadas con flores y ramas o con oropeles de color rosa y verde, en las que se apiñaban, sobre una pila de colchones y cojines, un grupo de niños y niñas, como pajaritos en su nido, tocando las palmas y cantando. Acompañándolas iban algunos jinetes con muchachas a la grupa, vestidas con el traje andaluz al completo. Incluso los curas iban a caballo. Nosotros habíamos acampado con los Murchies y algunos gibraltareños en un pequeño eucaliptal (24), pero como Katie Murchie estaba de malhumor y Gamel (25), afónica con un dolor de la garganta, decidieron retirarse pronto, Hetty (26) y yo nos fuimos por nuestra cuenta. Cada caseta o casa tenía delante una terraza sombreada con ramas, donde bailaban y cantaban las parejas y donde enseguida nos acogieron e invitaron a unos vasos de vino. Bailaban significa, por supuesto, que bailaban flamenco, así que Hetty, que es una soberbia bailarina de jazz, después de que Carmen (27) le diera algunas nociones, se lanzó a bailar una sevillana con mucho entusiasmo. Con su cara ancha de muñeca, sus grandes ojos pintados de rímel y su pelo oscuro fluyendo salvajemente sobre el mantón de seda blanca que llevaba puesto, lucía locamente provocativa y exótica, mientras que yo vestía mi intachable traje blanco de alpaca. ¡Olé! ¡Olé! ¡Qué alegría! Dondequiera que íbamos, estallido de palmas, sones de castañuelas, voces cantando y torbellino de cuerpos. Estábamos aniquilando el tiempo; estábamos ahogándolo en nuestra propia alegría. Una y otra vez deambulábamos por la arena amontonada de choza en choza, de taberna en taberna, mientras que el día se desvanecía y se encendían lamparitas de aceite, y la luna se posaba sobre los altos eucaliptos y pequeñas fogatas salpicaban el campamento y la llanura circundante. Hasta que de pronto distinguimos en la oscuridad algunas caras conocidas, que resultaron ser del grupo de la Cónsula (28), y regresamos con ellos para la cena. Jaime (29) había traído consigo a su cocinero y a su mayordomo (dos mariquitas gordos), Bill había traído al pequeño Rafael (30) y su casa (por la que había pagado 4,000 pesetas) en realidad tenía el sitio justo para una cocina-comedor, con una mesa y sillas, y tres o cuatro diminutos cubículos para dormir. Bill y Annie (31) habían montado una tienda para sí mismos en el patio.

¡Olé!, ¡olé!, ¡olé!, ¡qué alegría! Allí estaban Jaime, los Fielding (32), Paddy Leigh-Fermor (33), Deborah Devonshire, (34) y dos o tres personas más. Nos besamos, bailamos, bebimos, comimos -para entonces todo el mundo estaba deliciosamente borracho- y luego vagamos juntos de aquí para allá y nos encaminamos a una fiesta que según Annie estaba llena de lesbianas. No podría decirlo. Sólo vi unas mujeres vestidas de flamenca y a hombres en mangas cortas y me dieron whisky. Entonces alguien llegó y se hicieron las presentaciones formales, y me di cuenta de que estaba sentado entre dos duquesas y 
hablando de remo (35) al Duque de Miranda y de que el hombre que había pellizcado en el trasero a Annie era un descendiente de Guzmán el Bueno, célebre en el siglo XIV y varias veces grande (de España). Nuestra duquesa, que se sintió fatigada, se quedó atrás.

Pero las calles eran más divertidas y enseguida me vi llevado a través de la oscuridad con Daphne, (36) Paddy y, por supuesto, con mi fiel Hetty, bebiendo en bares y comiendo churros. Eran las cinco, nadie se había ido a la cama, las palmas y las castañuelas seguían sonando, seguían el baile y el cante, hasta que por fin regresamos a la caseta de Bill, donde nos ofrecieron un cuchitril para dormir. Nos desvestimos un poco, nos acostamos en un colchón de paja y nos quedamos dormidos envueltos en una sola manta, muy cerca el uno del otro para conservar el calor. Rompió el día.

Nos levantamos a las nueve. Todavía las calles estaban llenas de gente que no se había acostado. Los bailes y palmas que había escuchado en mis sueños ya estaban en pleno apogeo. Alrededor de cada casa, alrededor de los límites de la acampada había miles de caballos, mulos y burros a los que les estaban dando de beber y comer. Bueyes en reposo masticaban forraje, mientras una luz dorada espesada por el polvo flotante, difuminaba las casas blancas y los verdes eucaliptos. Tomamos coñac y churros para desayunar -no pude encontrar café- y volvimos a la acampada a buscar a Gamel. Nos encontramos con las caras de desaprobación de los gibraltareños, el ceño fruncido de Katie. Gamel, sin embargo, había dormido bien en la pequeña tienda con mi manta y con la suya, aún tenía perdida la voz y no podía hablar con nadie. Los tres nos pusimos en marcha. Hetty había recibido varias invitaciones para montar y poco después un caballero andaluz (37) muy apuesto apareció en un bonito caballo y la montó a la grupa. La llevó de caseta en caseta, donde les sacaban y les ofrecían bebidas, y de vez en cuando giraba hacia ella su cara afilada bajo su recio sombrero cordobés y le cantaba una copla. Gamel y yo caminamos en medio del polvo mirando cómo los jinetes galopaban y luego nos sentamos en una choza hasta que ella (38) se reunió con nosotros. Hetty y yo habíamos sido invitados a almorzar por un joven pintor, pero -muy en contra de su voluntad- dejé que se fuera sola pues me di cuenta de que debía hablar con la enfurruñada Katie y aplacarla comiendo la carne de borrego que ella había traído. Estaba de malhumor, disgustada con todo -iqué poco les gusta a las mujeres de mediana edad que los hombres de su generación gocen de la compañía de jovencitas!--, mientas que Guy estaba conduciendo hacia Gibraltar con Robert Louis Stevenson, como yo lo llamaba, quien saltando de un tejado para presumir a la manera de Virginibus Puerisque (39) se había roto el tobillo. Entonces acudíal rescate de Hetty, todos echamos una siesta bajo los árboles y de nuevo con ella, pues la pobre Gamel estaba demasiado afónica para enfrentarse al grupo de la Cónsula.

Cenamos otra vez con los Davis a las diez y después salimos con Jaime y Daphne para ver la procesión (40). Maravillosos fuegos artificiales y cohetes, grandes multitudes y siempre este apasionante, sugestivo sonido de palmas y castañuelas. Al paso de los estandartes se cantaban saetas (41). Una y otra vez, ya más que un poco bebidos, con extraños encuentros en la oscuridad, dando traspiés por la arena, parando para beber o mirar a la gente bailando, hasta que a las cinco volvimos a la casa de los Davis. Entonces nos desvestimos y nos acostamos envueltos en una manta en nuestro cubículo, mientras Hetty lloraba con un exceso de emoción y hablaba de sí misma con más intimidad de la que nunca antes lo había hecho. Sentí su cara en mi mejilla, su pelo cayendo sobre mí, abrazados, y envueltos en la deliciosa neblina de una olímpica (42) borrachera. Llegaban de fuera los sonidos de la romería y yo sentí una especie de felicidad que jamás había pensado que volvería a sentir a mi edad. Un millar de bendiciones para ella. Siempre respetaré su lealtad hacia su marido, a quien le reserva una cosa, porque, dentro de los límites que el afecto y la embriaguez permiten, ella ha sido muy buena conmigo. ¡Oh, qué feliz me sentía!

Nos levantamos temprano para ver la última procesión. Sacan a la Virgen de su santuario y la pasean por la aldea, mientras los hombres jóvenes empujan y luchan por el honor de llevarla. La veíamos tambalearse y dar vueltas por las calles. Nuestra Señora del "Rock and Roll" (43), se movía a empujones de un lado a otro, cayéndose y levantándose. ¡Viva la blanca Paloma! ¡Viva la Virgen del Rocío! ¡Viva, Viva! Todo pueblo grande de las provincias de Huelva y Sevilla tiene su casa de hermandad y, cuando (la imagen) se aproximaba a cada una de ellas, un cura, totalmente borracho (44), se veía subido en volandas, arrastrado hacia ella y entonces, con un extraordinario aleteo de brazos, le echaba un torrente de piropos a su apacible y triste cara de muñeca. De vez en cuando una mujer enloquecía, se apresuraba hacia el paso, debatiéndose entre los hombres que lo llevaban y, con una cara por la que corría un río de lágrimas, gateaba hasta él para tocar su manto. ¡Viva! ¡Viva! ¡Gran emoción! Con tres horas de todo esto ya habíamos tenido bastante, así que nos fuimos a una taberna con Gamel, a la que habíamos traído con nosotros. Por fin los cohetes nos avisaban de que la Virgen había regresado sana y salva a su santuario y nos fuimos a nuestro 
campamento a almorzar. Todo el mundo se marchó (45). Adiós a los caballos y a sus jinetes, adiós a las carretas, adiós a las nubes de polvo y a la dorada luz y a las palmas. Hetty yo visitamos por última vez la caseta de la Cónsula; a las cuatro regresó Guy y partimos hacia Moguer, donde nos bañamos en el mar (46), y continuamos hasta Huelva para dormir.

No, nunca me olvidaré del Rocío mientras viva: su asombrosa belleza y su alegría, lo más maravilloso que he visto en mi vida. Y qué suerte haberlo visto con Hetty, pues pude sumergirme en él y beber su frenesí pagano y su júbilo, y acabarlo bajo una manta, de manera correcta. He sido demasiado afortunado, como Daphne me decía, he sido demasiado afortunado. Debo terminar mi novela y morirme pronto, rápida y repentinamente, sin dejar rastro de la miserable vejez (47). Amo demasiado a la vida para aceptar cualquier racionamiento de ella, cualquier disminución de su dolor o de su gozo. No quiero convertirme en un gruñón en vida. Entretanto que la gente se ría de mis romances sexagenarios como le plazca (48). Soy lo que siento, iy al carajo el mundo de los envidiosos!

¡Y qué estimulante es la felicidad! La mayoría de la gente de la Cónsula estaba agotada cuando nos fuimos y a mí normalmente me afecta mucho la falta de sueño. Pero en el camino de vuelta mi entusiasmo irritaba a todo el mundo, y yo no tenía ninguna sensación de resaca. Hetty es una permanente inyección de alegría, pero no estoy enamorado de ella lo más mínimo ni espero echarla de menos cuando se vaya. Sólo siento un tremendo afecto por ella y una tremenda gratitud. Y cuando miro el cuadro que ella pintó de la procesión, es, como todos sus cuadros: como un sueño y triste. Esta pequeña bomba de hidrógeno de la alegría, la calidez y el afecto tiene un nivel más profundo que nadie toca nunca, que nunca alcanza a ver. Los seres humanos son muy misteriosos.

Gamel se va a Londres el 14 . Voy a estar aquí a solas con Hetty por unas tres semanas, mientras su marido espera sentirse normal de nuevo y recibir su pensión mensual de $149 \$$, que ha sido retenida tres meses porque él no les había notificado en tiempo la muerte de su primera esposa y por eso les debe $300 \$$. Esto, en cualquier caso, es lo que este tipo extraño dice. Todavía no sé si mi artículo sobre El Prado ha sido aceptado: si no, vamos a tener que ahorrar ya que últimamente he estado gastando más de la cuenta. Así que Viva la Blanca Paloma, y que su encanto siga bendiciéndome un poco más, para que esté en condiciones de volver a visitarla el próximo año (49). No estaría mal que alquilaras una caseta con nosotros y nos acompañaras.

Cariñosamente,

Gerald

Hice el mágico estudio $\underline{(50)}$

De la dicha ineludible

Salud a ella, cada vez

Que canta el gallo francés.

¡Oh estaciones, oh castillos!

Anexo II: Letter (51) from Gerald Brenan to Ralph Partridge

Churriana, Malaga, 29 May, 1958

Dearest Ralph, 
And now I must really sit down and write you an account of the Romeria of the Virgen del Rocio, the Virgin of the Dew, where I spent four of the happiest and most delicious days of my life. We left with the Murchies on Saturday morning, got to Seville by four and to the Rocio a couple of hours later. Imagine a great sandy plain, partly wooded with umbrella pines and eucalyptus and giving onto the Marismas. Imagine a straggling encampment-village of booths and single-storied houses separated by wide sandy streets and squares, and completely empty and deserted except during these days in the year. And then imagine 12,000 men, women and children, 1,000 riding horses, 300 ox waggons, and countless mules and donkeys. As they move about on the sandy streets clouds of dust and sand rise into the air. Clapping of hands, noise of castanets and flamenco singing resound everywhere.

We arrived as the procession in the Virgen's shrine and hermitage was forming. It consisted of a long defile of covered ox-wagons decorated with flowers and branches or else with rose or green tinsel: inside each of them on a pile of mattresses and cushions sat a cluster of girls and children, like young birds on their nest, beating their palms and singing. Accompanying some were horsemen with girls riding pillion behind them, all in full Andalusian dress. Even the priests rode on horseback. We had camped with the Murchies and some Gibraltar people in a small eucalyptus wood, but as Katie Murchie was in her worst mood and Gamel, speechless with a bad throat, wanted to retire early, Hetty and I got off by ourselves. Each little caseta or house had a branch-shaded veranda in front of it where couples danced and sang and we were quickly picked up and invited in to glasses of wine. Dancing of course meant flamenco dancing, but Hetty, who is a superb dancer of jazz, had had a lesson from Carmen and threw herself into the sevillana with great spirit. With her broad doll's face and great mascara-painted eyes and dark hair streaming down wildly over the white silk shawl she was wearing, she looked madly tartish and exotic, while I wore my correct white alpaca suit. Olé! olé! qué alegria! Everywhere we went, clap clapping of hands, rattle of castanets, voices singing, and whirl of bodies. We were annihilating time; we were drowning it with our gaiety. On and on we drifted through the deep sand from booth to booth, from tavern to tavern while the day faded and little oil lamps were lit and the moon bent down over the tall eucalyptus trees and little fires dotted the encampment and the plain around. Till suddenly we saw through the darkness familiar faces and there were the Consuela party and we went back with them to supper. Jaime had brought his cook and butler (two fat pansies), Bill had brought little Rafael and their house (for which he had paid 4,000 pesetas) actually had a fair sized kitchen-sitting room with a table and chairs and three or four little cubby holes for sleeping in. Bill and Annie had put up a tent for themselves in the yard.

Olé!, olé!, qué alegría! Jamie, the Fieldings, Paddy Leigh-Fermor, Deborah Devonshire, and one or two other people were there. We kissed, danced about, drank, eat -everyone was delightfully drunk by this time- and then we all wandered out together and made our way to a party which Annie told me was full of lesbians. I couldn't tell. I just saw women in Andalusian costume and men in shirt sleeves and was given whiskey. Then someone came and formal introductions had to be made and I realized that I was sitting between two duchesses and talking about rowing to the Duke of Miranda and that the man who had pinched Annie's bottom was a descendant of Guzman el Bueno, of $14^{\text {th }}$ century fame, and a grandee several times over. Our duchess, who was feeling tired, had been left behind.

But the streets were better fun and soon I was pushing through the darkness with Daphne, Paddy and of course my faithful Hetty, drinking in bars and eating churros, or oil fritters. It was five o'clock, no one had gone to bed, clapping of hands and castanets still going on, dancing and singing still going on, until at last we were back in Bill's caseta, where we were offered a little cubby hole to ourselves to sleep in. We undressed a bit, lay down on a mattress of canes and fell asleep wrapped in a single blanket, very close together to keep warm. Day was breaking.

We were up by nine. Already the streets were full of people who had not gone to bed. The dancing and clapping which I had heard through my dreams were still in full swing. Round each house, round the edges of the encampment thousands of horses, mules and donkies were being watered and fed. Couched oxen munched their fodder while a golden light thickened by the floating dust dissolved the white houses and the green eucalyptus trees. We had cognac and churros for breakfast -couldn't find coffee- and went back to the camp to look for Gamel. Disapproving faces of the Gibralterians met us, scowl from Katie, but Gamel had slept well in the little tent with my blanket as well as her own, yet had no voice at all left to speak with. The three of us sallied out. Hetty had had several invitations to ride and soon a very handsome and Andalusy caballero turned up on a beautiful horse and she mounted behind him. He took her from caseta to caseta 
where drinks were brought out and offered, and every now and then he turned his knife-like face under its stiff Cordoba hat to her and sang a copla. Gamel and I walked about in the swirling dust watching the horsemen galloping by and then sat in a booth till she rejoined us. Hetty and I had been invited to lunch by a young painter, but I left her -much against her will- to go alone as I felt I must talk to the sulking Katie and placate her by eating from the joint of mutton she had brought. She was in a bad mood, hating everything -how middle aged women dislike the men of their generation enjoying the society of girls!- while Guy had driven off to Gibraltar with Robert Lewis Stevenson, as I called him, who had jumped off a roof in a Virginilius Puerisque mood of show off and broken his ankle. Then I rescued Hetty, we all had a siesta under the trees and off again with her, as poor Gamel felt too voiceless to face the Cónsula family.

We dined again with the Davises at 10 and then went out with Jaime and Daphne to see the procession. Marvellous fireworks and rockets, huge crowds and always this exciting, inviting sound of clapping hands and castanets. Saetas were sung as the banners passed. On and on, now pretty drunk, with strange encounters in the dark, stumbling in the sand, stopping for drinks or to watch dancers, till at 5 we got back to the Davises' caseta. Then we undressed and lay wrapped in a single blanket in our cubby hole, while Hetty cried with excess of emotion and talked more intimately than she had ever done about herself. I felt her face against my cheek, her hair falling over me, our arms round one another, a delicious mist of Olympian drunkenness enveloping us. The sounds of the romeria went on outside and I felt a kind of happiness I never thought at my age to have felt again. A thousand blessings on her. I shall always respect her loyalty to her husband, for whom she reserves one thing, because within the limits of what affection and drunkenness allow she has been so good to me. Oh, I felt happy!

We got up early to see the last procession. The Virgin is taken out of her sanctuary and borne around the village, while the young men push and fight for the honour of carrying her. We watched her staggering and rolling round the place. Our Lady of Rock and Roll, shoved from one side to the other, toppling and heaving. Viva la blanca Paloma! Viva la Virgen del Rocio! Viva, Viva! Every large pueblo of the provinces of Huelva and Seville has its confraternity house and as she came near to each of these, a priest would be lifted up in the air, rammed towards her and then with great flapping arms, completely drunk, he would shout out in her quiet sad doll's face a stream of piropos. Now and then a woman went mad, rushed towards the float, pushed through the men carrying it and with a face streaming with tears tried to climb onto it to touch her veil. Viva, Viva! Gran emoción! Till after three hours of this we had had enough and with Gamel, whom we had brought with us, we retired into a tavern. At last the rockets showed the Virgin had got back safe and sound to her shrine and we went off to our camp for lunch. Everyone was leaving, Goodbye the horses and their riders, goodbye the ox waggons, goodbye the clouds of dust and the golden, golden light and the clapping of hands. Hetty and I had a last visit to the Consuela caseta, then at 4 Guy returned and we set off for Moguer where we bathed in the sea and on to Huelva to sleep. Home next day, stopping for an hour in Seville to see the cathedral.

No, as long as I live I shall never forget the Rocío, its amazing beauty and its gaiety, the most wonderful thing I have ever seen in my life. And what luck I had to see it with Hetty for then I could plunge into it and drink its pagan frenzy and gaiety and end it under a blanket in the right way. I have been too lucky, as Dalphne left saying to me, I have been too lucky. I must finish my novel and die soon, quickly and suddenly, and leave no trail of miserable old age. I love life too much to accept any rationing of it, any diminution of its pain or its delight. I don't want in life to be a croaker. Meanwhile let people laugh at my sexagenarian goings on as they please. I am what I feel, so fuck off the world of the envious!

And how invigorating happiness is! Most of the Cónsula party were wilting when we left and usually I feel a good deal any lack of sleep. But on the return journey my high spirits irritated everyone and I have not felt any hang over at all. Hetty is a permanent injection of gaiety and yet I am not in love with her in the very least and don't expect to miss her when she leaves. I just feel a tremendous affection for her and a tremendous gratitude. And then I look at the picture she has painted of the procession: like all her pictures it is dream-like and sad. This little hydrogen bomb of gaiety and warmth and affection has a deeper level which one never touches, never espies. Human beings are very mysterious.

Gamel is leaving on the 14th for London. I shall be here alone with Hetty for some three weeks, when her husband expects to feel normal again and to be in receipt of his monthly pension of $\$ 149$, which had been stopped for three months because he hadn't notified them in time of the death of his first wife and so owes them $\$ 300$. That, anyhow, is what this strange man points out. I have not yet heard if my Prado article has 
been accepted: if not, we are going to have to economize as lately I have been spending rather a lot. So Viva la Blanca Paloma, and may her spell continue to bless me a little longer, so that I shall be able to visit her again next year. You could do worse than hire a caseta with us and accompany us.

With tender love,

Gerald

J'ai fait la magique étude

Du bonheur, que nul n’elude.

Ô vive lui, chaque fois

Que chante le coq gaulois.

Ô saisons, ô châteaux.

\section{Notas}

1. Gamel Wolsey (1895-1968), poeta, escritora y traductora norteamericana.

2. Hetty (en realidad, Mary) MacGee, una joven británica de vida bohemia y aventurera.

3. Supimos de la existencia de esta carta a través de The Interior Castle, la espléndida biografía que Jonathan Gathorne-Hardy dedicó a Gerald Brenan. En el capítulo dedicado a Hetty MacGee habla brevemente de este viaje al Rocío y cita la procedencia de su información: una carta de Gerald a Ralph Partridge fechada el 29 de mayo de 1958. Esta carta se encuentra depositada en los archivos del King's College, de la Universidad de Cambridge (King's College Archive Centre, Cambridge. Reference GBR/0272/PP/FCP/6/1/19/2/6). Forma parte del legado de Frances Partridge, la segunda esposa de Ralph. Queremos agradecer a los herederos de Gerald Brenan el permiso -obtenido gracias a sus agentes literarios, la Hanbury Agency- para publicar su texto original y su traducción al español. Asimismo, expresamos nuestro agradecimiento a la Universidad de Cambridge, que nos facilitó en su día una copia del original. Y, muy especialmente, a Dan Mullins, antropólogo y estudiante de doctorado de la Universidad de Oxford, quien, antes de que se nos concediera ese permiso, transcribió a mano todo el texto, venciendo las dificultades de la peculiar caligrafía de Brenan.

4. Ralph Partridge (1894-1960), escritor, periodista especializado en crítica literaria miembro del Grupo de Bloomsbury.

5. Las citas de Gerald Brenan, extraídas de la carta a Ralph Partridge, han sido reproducidas con el permiso del Estate of Gerald Brenan, c/o The Hanbury Agency Ltd, 28 Moreton Street, London SW1V 2PE. Copyright (C) 1958 Gerald Brenan. All Rights Reserved. Traducción de los autores.

6. lan Gibson (1987: 173 y 178) pone de relieve "su gran contribución al hispanismo y a la imagen que de España se tiene en el mundo" y dice de él que "es probablemente el angloandaluz más cabal de todos los tiempos".

7. Las cifras de asistentes a la romería son sólo estimaciones aproximadas, no pocas veces exageradas. 
En todo caso, reflejan su rápido incremento.

8. Según Álvarez Gastón (1987: 115), "sin duda, el hecho más decisivo en la historia del Rocío".

9. El otro era Don Modesto Laza Palacios, un farmacéutico de Málaga que había sido alcalde de la ciudad. "Era un erudito de los que tanto gustaban a Gerald: feo, vitalista, de inmensa energía y curiosidad insaciable, capaz de leer en francés, alemán e italiano, era el principal botánico de Málaga, experto en arqueología, una mina de información sobre la vida y las costumbres de España, sobre todo en el terreno de lo sexual. Hicieron juntos varias expediciones -botánicas o en busca de una cueva de Pompeya o de una fábrica griega- y Modesto llegó a ser prácticamente el único amigo íntimo de verdad que tuvo Gerald entre los españoles" (Gathorne-Hardy 1992: 410. Cita extraída de la traducción al español de Miguel Martínez-Lage 2003: 561).

10. Gathhorne-Hardy (1992: xi) estima que la correspondencia de Brenan ronda los 3-4 millones de palabras, contando sólo con las cartas que se han conservado.

11. En su enojada y en general negativa reseña de la biografía de Gathorne-Hardy y del propio Brenan, John McCormick (2008: 91) apunta, sin embargo, que Brenan tuvo "talento, un genuino talento, para la prosa en la historia, la correspondencia y la autobiografía".

12. Cita extraída de la traducción al español de Miguel Martínez-Lage 2003: 815.

13. Según Pitt-Rivers (1987: 164), Brenan "nunca tuvo la pretensión de ser etnógrafo... Pero tenía las cualidades morales para hacerse un buen antropólogo".

14. Lisón Tolosana, en su presentación de una edición en español de Al sur de Granada (2011: 10), considera esta obra como un "eslabón especial" dentro de la "cadena bibliográfica" trisecular de relatos sobre España escritos por viajeros británicos. Malpartida (2003: 47) indica que Brenan se describió a sí mismo como "un romántico en cuanto a las ideas y sentimientos y un clásico en cuanto al estilo".

15. Para conocer más detalles sobre la evolución de la Aldea del Rocío, véase González Faraco y Murphy 1999.

16. Desde la Romería de 2013, este desfile ritual ha sido dividido en dos fases, a causa de su larga y extenuante duración, por el número de hermandades involucradas en él (actualmente, 114). En la primera fase, que se desarrolla el viernes por la tarde, participa un tercio de ellas, las más recientes; en la segunda fase, el sábado durante buena parte del día, el resto. Los ritos de la Romería han sufrido muchas modificaciones de este u otro tipo a lo largo del tiempo, pero se han hecho mucho más frecuentes en las últimas décadas, como consecuencia del proceso de masificación.

17. En Al sur de Granada abundan también las reflexiones personales. Algunos de sus pasajes sugieren, es cierto, una cierta perspectiva etnográfica, pero con notorias dosis de subjetivismo. Brenan quiso documentar la vida y costumbres de la gente de la Alpujarra, y se esmeró en ello, pero de tal forma que su relato se sostiene con frecuencia en sus propias experiencias e intereses. Esta obra no tiene ni la estructura ni el tono, ni por supuesto el rigor metodológico, de una monografía etnográfica de su época. Pero son tales el poder de observación y la habilidad descriptiva de Brenan que a veces su lectura produce una cierta impresión de verosimilitud etnográfica, aunque sin síntesis antropológica. Aunque es un libro repleto de observaciones sutiles y fascinantes, resulta muy selectivo en cuanto a sus tópicos, al igual que la carta objeto de este artículo.

18. Quizás no haya un ejemplo más revelador de ese rasgo de la personalidad de Brenan que el trato que dispensó a Juliana, la madre de su hija, según lo narra Antonio Ramos Espejo (2010).

19. Traducida por Michael D. Murphy y Juan Carlos González Faraco. La publicación de esta traducción y del original se hacen con el permiso del Estate of Gerald Brenan c/o The Hanbury Agency Ltd, 28 Moreton Street, London SW1V 2PE. Copyright @ 1958 Gerald Brenan. Todos los derechos reservados.

20. Ralph Partridge (en realidad, Reginald Sherring Partridge) nació en 1894. Fue el mejor amigo de Brenan. Su amistad pasó por frecuentes altibajos, pero duró hasta la repentina muerte de Ralph en 1960. Se habían conocido durante la I Guerra Mundial, en la que ambos participaron. Partridge formó parte del Grupo 
de Bloomsbury, al que accedió a través de Dora Carrington y Lytton Strachey. Acabó casándose con Carrington, enamorada a su vez de Strachey, que era homosexual, y los tres vivieron juntos durante algunos años. Strachey murió en 1932 y Carrington se suicidó podo después. Brenan había tenido un romance con ella a raíz de la visita del grupo a Yegen en 1922. Tras la muerte de Dora, Ralph se casó en 1933 con la escritora, también de Bloomsbury, Frances Marshall, con quien ya mantenía relaciones, conocidas por Dora, desde hacía tiempo. Esta carta forma parte, precisamente, del legado de Frances Partridge.

21. Guy y Katie Murchie. Guy Murchie (1907-1997), norteamericano, fue, entre otras cosas, escritor, fotógrafo, reportero y corresponsal de guerra del Chicago Tribune, instructor de vuelo, y practicante del bahaísmo (o fe Bahá'i). Brenan lo menciona en el prefacio de South from Granada. Se casó en 1949 con Katie Rautenstrauch, una refugiada prusiana de la Alemania nazi. Su matrimonio con Guy Murchie duró hasta su muerte en 1986. Para conocer mejor la cronología de Guy Murchie, véase: http://kaweah.com/blog/2009/10/30/a-guy-murchie-timeline/

22. Estos datos no provienen de una fuente fiable; son sólo estimaciones de Brenan.

23. Se refiere a la Entrada oficial de las Hermandades, uno de los rituales centrales de la Romería del Rocío.

24. En esos tiempos este pequeño bosque de eucaliptos, plantado en 1925, estaba situado a las afueras de la Aldea, y su papel era precisamente el de ser un lugar de refugio y acampada para quienes no tenían casa o choza.

25. Gamel Wolsey (1895-1968), escritora, principalmente poeta, norteamericana. Fue la esposa de Gerald Brenan.

26. Hetty MacGee (en realidad, Mary MacGee, de soltera Scholten), joven británica, de padre holandés y madre irlandesa, a la que Brenan conoció en 1958. En ese momento vivía en la costa de Málaga y llevaba una vida bohemia y desordenada, en la que no faltaban las drogas. Brenan la ayudó, viajó con ella, y la acogió (a ella y a su hijo) en su casa. Esta peculiar y tormentosa relación duró aproximadamente hasta 1963.

27. Carmen, hija de Rosario, cocinera de Brenan en Yegen y más tarde en Churriana.

28. La Cónsula estaba "a tiro de piedra" de la casa de Brenan en Churriana, Málaga (Fielding 1986: 168). Era una antigua hacienda agrícola con una especie de mansión, o "casa grande", que había tenido entre sus muchos propietarios a Juan Roose Kupckovius, cónsul de Prusia, de ahí su nombre. En 1958 era propiedad del matrimonio norteamericano formado por Bill y Anne Davis (de soltera, Bakewell), quienes se la habían comprado en 1953 a sir Herbert Barker. Anne era hermana de Jean Bakewell, quien una vez estuvo casada con Cyril Connolly, escritor inglés y huésped habitual de la Cónsula, centro de una intensa vida social. Por la Cónsula pasaron invitados como Hemingway, Orson Wells, Bertrand Russell, David Niven, entre otros, y, por supuesto, Gerald Brenan, que era un asiduo de sus fiestas y tertulias. Brenan conoció a los Davis en 1953 a través de Connolly, según se deduce de una carta a Ralph Partridge de 16 de febrero de ese año. En otra carta de 8 de mayo de 1954, escribe: "La señora Davis, una mujer muy simple, ingenua, lo adora (a Cyril Connolly) y él le escribe con el tono más amable, más afectuoso, como un hermano. Bill Davis lo admira, pero es un cínico" (Fielding 1986: 199).

29. Jaime de Parladé y Sanjuanena, sevillano de familia noble, desde 1994 tercer marqués de Apezteguía. Vecino de Brenan en Churriana. Se casó con la pintora Janetta Wolley en 1971. No lo podríamos asegurar, pero es probable que la idea de este viaje al Rocío saliera de él.

30. No hemos podido averiguar la identidad de este personaje.

31. Bill y Anne Davis.

32. Xan (Alexander) Fielding, y su entonces esposa Daphne Bath. Fielding recopiló una parte de la copiosa correspondencia de Brenan y Ralph Partridge en Best of Friends, 1986.

33. Paddy (Patrick) Leigh Fermor. 
34. Deborah Devonshire, duquesa de Devonshire, una de las hermanas Mitford, amiga de Patrick Leigh Fermor.

35. Entre la clase alta británica es común la afición a las competiciones de remo. Esta anécdota puede ilustrar el marcado contraste entre el Rocío de las casas de la aristocracia y el Rocío mucho más popular de la calle.

36. Daphne Bath, esposa de Xan Fielding.

37. Aunque hemos traducido "Andalusy" por "andaluz", esta expresión es casi intraducible. Es una palabra que sugiere frivolidad. Brenan se vale de la ironía para expresar su burla y su desdén por este individuo que coqueteaba con su querida Hetty. Unas líneas más adelante lo describe con una "cara afilada".

38. Se refiere a Hetty.

39. Una alusión a la colección de ensayos (1881) de Robert Louis Stevenson con este título, que, traducido del latín, quiere decir literalmente "para niñas y niños".

40. Brenan usa la palabra "procesión" para nombrar los distintos rituales de la Romería. Esta vez se refiere al rosario nocturno. Quizás sea esta la más clara evidencia del relativo desinterés de Brenan por los aspectos religiosos de la romería. No hizo el menor esfuerzo por aprender a distinguir con sus propias denominaciones los distintos actos rituales que se desarrollaban en la Aldea del Rocío. A todos ellos los llama "procesiones". Tampoco usa la palabra "simpecado", tan común en la peregrinación, sino una expresión más genérica, "estandarte".

41. Brenan está confundiendo las sevillanas con las saetas. Es extraño que habiendo leído tanto sobre las coplas andaluzas, cometiera este error. La saeta es un cante circunscrito a unos rituales muy específicos, los de la Semana Santa, extraordinariamente distantes de una celebración como El Rocío.

42. Podemos leer esta expresión, "olímpica borrachera", como una referencia religiosa culta, típica de Brenan. Quizás está haciendo alusión a las bacchanalia en honor del dios Baco. En todo caso, la comparación del Rocío con una bacanal es muy corriente, sobre todo entre sus más críticos, pero también entre aquellos que quieren ver en el Rocío una conexión con ritos paganos precristianos. En el caso de Brenan, esta comparación no tiene nada de negativa, sino todo lo contrario.

43. Obviamente, esta frase tiene un doble sentido. Brenan se vale con perspicacia de la analogía entre los movimientos de este baile, tan popular en esos años, y los que describe el paso de la Virgen del Rocío durante la procesión del lunes de Pentecostés: "shoved from one side to the other, toppling and heaving".

44. Puede que se trate de una proyección del propio Brenan, y puede que también haya querido poner una nota anticlerical, algo cínica, en su relato. En todo caso, es muy improbable que viera a un cura "borracho", diciendo salves durante la procesión; más bien emocionado y exhausto, como si hubiera entrado en trance, sumergido plenamente en el ambiente enfervorizado y exaltado de la procesión.

45. Cien años antes (1858), otro visitante extranjero ilustre, el francés Antoine de Latour, describió de manera similar este mismo momento, cuando finaliza la procesión y la Virgen regresa a su santuario. En poco tiempo todo el mundo desaparece y la Aldea recupera su silencio y su vacío. A. de Latour, La Baie de Cadix, 1858 (cap. VII, Notre Dame du Rocio).

46. Debe referirse seguramente a la playa de Mazagón, cercana a Moguer y Huelva.

47. La carta está salpicada de referencias, como ésta, a su preocupación por el envejecimiento. Según sus palabras, la muerte es preferible a la "miserable vejez". Sin embargo, a Brenan aún le quedaban casi treinta años de vida. En ese dilatado periodo publicaría tres autobiografías, dos novelas y otros trabajos. El Rocío, en esas tres décadas, experimentaría un prodigioso crecimiento y una extraordinaria expansión.

48. Una reflexión que hubiera sido muy del gusto de Góngora, un poeta al que Brenan había leído mucho y al que le dedicó un capítulo entero en su The Literature of the Spanish People (1951).

49. Volvió al Rocío, que sepamos, diez años más tarde, en 1968, acompañado nuevamente de una chica 
joven, Lynda Nicholson. Su mujer, Gamel, había muerto unos meses antes. Véase la carta de Brenan a Julio Caro Baroja de 4 de junio de 1968 (Caro 2005: 142-143 y 234-235). También se cita esta visita en Gathorne Hardy 1992.

50. Brenan elige muy bien al autor, Arthur Rimbaud, y el texto. Es parte de un poema de 1872, que tiene tres versiones, la última de ellas incluida en su libro Une Saison en Enfer, el único que publicó él personalmente (1873). Significa para Brenan un canto, un brindis a la felicidad, en momentos de extremada excitación tras su visita al Rocío.

51. This letter from Gerald Brenan to Ralph Partridge is located in the King's College Archive Centre, University of Cambridge. Reference GBR/0272/PP/FCP/6/1/19/2/6. It was originally transcribed on December 3, 2012 by Dan Mullins. A photocopy was provided by the Archive Centre from which this corrected transcription was produced by Michael Murphy and J. Carlos González Faraco. The letter is reproduced by permission of the Estate of Gerald Brenan c/o The Hanbury Agency Ltd, 28 Moreton Street, London SW1V 2PE. Copyright ( 1958 Gerald Brenan. All Rights Reserved.

\section{Bibliografía}

Adame y Muñoz, Serafín

1849 "Feria del Rocío", en Vicente Álvarez Miranda (ed.), Glorias de Sevilla. En armas, letras, ciencias, artes, tradiciones, monumentos, edificios, caracteres, costumbres, estilos, fiestas y espectáculos. Sevilla, Carlos Santigosa Editor: 95-101, parte III.

Álvarez Gastón, Rosendo

1974 El Rocío a examen. Pasado, presente y futuro fe la devoción mariana rociera. Almonte, Huelva, Editorial Católica Española.

1981 Las raíces del Rocío. Huelva.

Bello, Luis

1928 Viaje por las escuelas de Andalucía. Sevilla, Consejería de Educación y Ciencia, 1998.

Brenan, Gerald

1957 South from Granada. London, Hamish Hamilton.

1975 Personal Record. New York, Alfred A. Knopf.

2003 Autobiografía. Barcelona, Editorial Península. Reúne las traducciones de A Life of One’s Own (1962) y Personal Record (1975).

Caro, Carmen

2005 Una amistad andaluza. Correspondencia entre Julio Caro Baroja y Gerald Brenan. Madrid, Caro Raggio.

Caro Baroja, Julio

1972 Los Baroja. Madrid, Taurus.

Chapman, Abel (y Walter Buck)

1910 "Our Lady of the Dew", en Unexplored Spain. New York, Longmans, Green and Co.: 82-87. Traducción al español: La España inexplorada. Sevilla, Consejería de Obras Públicas y Transportes, Junta de Andalucía, 2006. Introducción de A. López Ontiveros.

Christian, William

1972 Person and God in a Spanish Valley. Princeton, Princeton University Press.

1978 Religiosidad popular: estudio antropológico en un valle español. Madrid, Tecnos.

Fielding, Xan (ed.) 
1986 Best of Friends: The Brenan-Partridge Letters. London, Chatto \& Windus.

Gathorne-Hardy, Jonathan

1992 Gerald Brenan: The Interior Castle. London, W. W. Norton. Traducción al español: Gerald Brenan: El castillo interior. Barcelona, El Aleph, 2003.

Gibson, lan

1984 "Gerald Brenan, vividor impenitente", en La imagen de Andalucía en los viajeros románticos y Homenaje a Gerald Brenan. Málaga, Diputación Provincial: 173-180.

González Faraco, J. Carlos (y Michael D. Murphy)

1999 "El Rocío: evolución de una aldea sagrada", Aestuaria (Huelva), n 6: 89-132. Reimpreso y revisado en Michael D. Murphy y J. Carlos González Faraco (eds.) El Rocío: Análisis culturales e históricos. Huelva, Diputación Provincial de Huelva: 55-92, 2002.

Jiménez de Madariaga, Celeste

1997 Más allá de Andalucía. Reproducción de devociones andaluzas en Madrid. Sevilla, Fundación Blas Infante.

Latour, Antoine de

1858 La Baie de Cadix: Nouvelles études sur l'Espagne. París, Michel Lévy Fréres, Libraires-Éditeurs. Traducción al español: La Bahía de Cádiz. Nuevos estudios sobre España, Diputación de Cádiz, 1986. Traducido por Inmaculada Díaz Narbona y Lola Bermúdez Medina.

Lisón Tolosana, Carmelo

1997 “Presentación”, a Gerald Brenan, Al sur de Granada. Barcelona, Tusquets, $10^{a}$ reimp., 2011.

López López, Antonio J. (y Antonio Muñoz Palomares)

1992 Gerald Brenan y la lírica popular. Dos canciones romance inéditas, Gazeta de Antropología, 9, artículo 17.

Lozano, María

1984 "Brenan y su círculo: de Londres a Andalucía", en La imagen de Andalucía en los viajeros románticos y Homenaje a Gerald Brenan. Málaga: Diputación Provincial: 181-206.

Malpartida, Juan

2003 “Gerald Brenan en el laberinto español”, Letras Libres (Madrid-México), mayo: 46-50.

2006 "Una amistad singular”, Letras Libres (Madrid-México), abril: 54-56.

Martínez Moreno, Rosa M.

1997 "La romería del Rocío en Andalucía: una fiesta de la posmodernidad”, Gazeta de Antropología, 13, artículo 5.

http://hdl.handle.net/10481/13566

McCormick, John

2008 Another Music: Polemics and Pleasures. New Brunswick, Transaction Publishers.

Murchie, Guy

1995 The Soul School: Confessions of a Passenger on Planet Earth. Santa Barbara, California, Fithian Press.

Murphy, Michael D. (y J. Carlos González Faraco)

1996 "Masificación ritual, identidad local y toponimia en El Rocío", Demófilo: Revista de Cultura Tradicional de Andalucía (Sevilla), 20: 101-119.

2013 "Intensificación cultural en El Rocío: una breve aproximación comparada a la devoción rociera”, Exvoto (Huelva), 3 (2): 99-119.

Ojeda Rivera, Juan F.

1987 Organización del territorio en Doñana y su entorno próximo (Almonte). Siglos XVIII-XX. Madrid, 
ICONA.

Padilla Díaz de la Serna, Santiago

2010 Rocío, sal y sol de Andalucía. La difusión nacional del Rocío, desde el siglo XIX hasta 1961. Huelva, Editorial Hergué.

Pitt-Rivers, Julian A.

1987 "Gerald Brenan como etnólogo", en La imagen de Andalucía en los viajeros románticos: y homenaje a Gerald Brenan. Málaga, Diputación Provincial: 161-170.

Ramos Espejo, Antonio

2010 Ciega en Granada. Murió buscando a su hija. La hija de Brenan. Sevilla, Andalucía Documentos.

Rodríguez Becerra, Salvador

1989 “La romería del Rocío, fiesta de Andalucía”, El Folklore Andaluz (Sevilla), 3: 147-152.

2005 "La religión de los andaluces", en Salvador Rodríguez Becerra (coord.) Proyecto Andalucía. Antropología. Tomo VI. Religión. Sevilla, Publicaciones Comunitarias.

Turner, Victor

1973 "The Center Out There: Pilgrim's Goal”, History of Religions, 21 (3): 191-230. 